ments were manly wilh ary plates, I will leave out of question the forms which the phenomenon may assume in wet-plate photography, and summarise the results of hundreds of experiments with dry plates iodised, bromo-iodised, ant bromised.

Witl a simpiy bromised film the amount of irradiation is extreme. The film is very translucent and the irradiation is of two kinds, that cansed by reflection from the back of the plate being by far the most extensive, but remediable by the usuai expedient of coating the back of the plate with red or black. colour, while the form noticed by $\mathrm{Mr}$. Aitken is perhaps partially inherent in bromised films, but to a much greater degree dependent on the nature of the pyroxyline. Two simples of pyroxyline made at different temperatures, and treated in precisely the same manner, differ somuch, that while one will, with the coloured backing, give scarcely a perceptible degree of irradiation, the other will develop it to an extent which n backing, nor even tinting the film with the aniline reds, will obviate. The former is generally a compact, lustrous film, scarcely to be distinguished from the glass itself, while the othex (both being used without preservative solution) will give a dull and dusty-looking surface, only capable of reflecting at very small angles. If with the latter a strip of blackened wood be laid on the film so as to cut across the lightest portions of the image thrown on it by the lens, the effect of the light will be found to spread behincl the strip of wood, sometimes to the extent of a centimetre; but I have never noticed the sharp limitation of this form of irradiation which Mr. Aitken observes, and which probably depends on the wet state of the film. It is cleariy, as he supposes, an agiation which is set up in the film, and whicl deoends for its propagation amongst the surrounding molecules upon a kind of chemical transparency in the film holding the bromide of silver. That this is to a great extent true is shown by two experiments: ( 1 ) a film which, in its simple state, gives considerable halation, will, when coated with albumen, especially if coagulated with nitrate of silver, oive none at all, or very little, though the ocular transparency is rathex increased than diminished by the albumen; (2) an emulsion prepared by exposing tit to the sction of nitrate of silver until it becomes structurally decomposed, and highly charged with bromide of silver, shows absolutely no irradiation under any circumstances even if the glass be not backed, and no kind of preservative used. The film in this case resembles unbaked porcelain in its whiteness, entire want of lustre, and in opacity, and the molecules of bromide of silver are more than usually free from any restraining influence which a preservative might be expected, reasoning from the usual action of the albumen, to exert. In these two cases of extreme translucency and opacity of the film there is almost an equai freedom from the phenomenon in cyuestion.

In the old albumen process with transtucent films the irracliation is imperceptible, and in the colloclio-albumen, where the film of albument is allowed to remain on the collodion, it is almost so; but in this case, as in all cases where the film is charged only with iodile of silver, there is another element which complicates the action. The bromide of silver is reduced ind situ while the iodicie requires a supply of silver from the developer from which to build up the image, in the one case the deposition being by reduction, in the other by accumulation. This alone would account for a wide difference in respect to irradistion, but will not account for all; as is proven by tho diverse results obtained from different bromide films, due to the varging struture of the material which ho!ds the bromide in place.

What Mr. Aitken calls "mólecular irracliation" (and which is not by any means the harmless thing he considers it in regard to ariistic photograplyy any more than to scientific) is unquestionably the great enemy of all photorraphic precision. I sesms, however, to be complicated with what I have been obliged to call structural irradiation, alluded to above, and depending, as I have said, on the mechanical rather than the chemic 1 condition of the pyroxyline of which the bulk of the film consists. The subject yet cemands much investisration, of a purcly empirical character, in order to determine the quality of vehicle for carrying the sensitive salts, neither chemica! analysis nor chemica. analory affording any indication of the true cause of the clifference between the two qualities of pyroxylene I have noted, nor do they, so far as I am aware, account for the difference between the action of collodion and albumen.

$$
\text { W. J, STillman }
$$

Altenburgh Gardens, Clapham Common, S.W., July i3

\section{OBSERVATORIES IN THE UNITED STATES*} II.

TEUT. M. F. MAURY was placed in charge of the new U.S. Naval Observatory, and entered on his duties with zealous purposes. He proposed in 1846 the immense astronomical work of a more extensive and precise cataloguing of the stars than Bessel's "Zone Observations" or Struve's "Dorpat Catalogue." Valuable results of the scheme, so far as it could be entered on, by the observations of Profs. Coffin, Walker, Yarnall, Hubbard, Keith, Major, and Ferguson, and Lieutenants Almy, Maynard, Muse, and others, have been lately reduced and published.

Two events marked this early part of the history with still more importance. Walker, in 1846 , proved that the now planet Neptune, just then discovered by Leverrier, had been catalogued as a star by Lalande in his "Histoire celeste" in 1793 ; and Walker, with Lieutenants Almy and Gilliss, was the very first to use, in 1846 , the new cliscovery of the tele raph to determine differences of longitude. The identification of Neptune with Lalande's star gave astronomers, in determining the new planet's orbit, the use of observations made fifty-two years before. It gave the American Nautical Almanac two years earlier ephemerides for the mariner. It bronght the observatory into prominence. The superintendency of Maury extended from I 845 to April 26, I 86 r, when he suadenly left the city to join the cause of the Scuth.

In 1861 Lieut. J. M. Gilliss was at length placed in charge. He re-established and vigorously pressed forward astronomical work as well as the duies of the "Hydrographical Office," a title which had been added to that of the Naval Observatory. After his very sudden death, his successor, Rear-Admiral C. H. Davis, carried forward the astronomical work with that eminent success which had been guaranteed by his previous astronomical tastes and occupancy on the Coast Survey and as superintendent of the Natical Almanac. Rear-Admiral B. F. Sands, succeedins him in the year I867, has most efficiently improved the opportunities of a longer superintendency to inaugurate and carry forward some of the most important astronomical operations of the day. The phenomena of the total cclipses of 1869 in the United States and of 1870 in the Mediterranean comntries werc closely observed.

Beyond the regritar and severely exacting astronornical routine of observations, two centres of interest have been recently occupying the utmost activities of the institu. tion; the reception, mounting; and use of the new grext equatorial, and preparations for the transit of Venus.

The great equatorial has but one near approach to it self in the diameter of its object-glass-that of the private establishment of Mr. R. S. Newall, at Gateshcadon-Tyne, whose telescope has an object-glass of $25 \mathrm{in}$, in diameter. The Naval Observatory glass has $26 \mathrm{in}$. cleat aperture. It is not easy to realise what this power is, and what it promises. The reader must imagine himself within a dome, itself $4 \mathrm{Ift}$. in cliameter and $40 \mathrm{ft}$, in lieight, looking through a tube made of three sections of steel stretching away for $32 \mathrm{ft}$. ; the whole telescope and its metallic base weighing about 6 tons.

In the dome, on a pier of mason-work, supported by $a$ pedestal, which is one block weighing $7 \frac{1}{\frac{1}{2}}$ tons, stands the tine equatorial made by Merz and Mähler, Munich, at a cost of 6,000 dols, its object-glass being valued at more than half that sum. The work of this instrument undor, successively, Profs. Ferguson, Walker, Hubbarel, and Hail, has been chiefly upon the smaller planets, the asteroids, and comets. Mr. James Ferguson was the first American to discover an asteroid, Euphrosyne, in 1854 , the thirtyfirst on a list which has been recently enlarged beyond even a hundred by Peters of Clinton and Watson of Ann

\footnotetext{
* Continued from p. res.
} 
Arbor. The object-glass of the equatorial has an aperture of 9.62 in and a focal length of $14 \mathrm{ft} .4 .5 \mathrm{in}$. Its powers of positive eye-pieces for use with its filar micrometer vary from 90 to 899 .

Descending from the dome, and passing the superintendent's office, in which are a most excellent mean-time clock, with others, in the electric circuit with the clocks at the departments, ticking each, beat for beat, the visitor finds himself in the library, now embracing nearly 6,000 volumes. These are mostly works of the highest standard value, astronomical and meteorological observations and discussions, some being as old as the year 1482 , others representing the full work of the European observatories and learned Societies to the present date.
From the library we pass into the transit-circle room, built in 1869 , to admire the beautiful instrument, with its collimators and its chronograph. The focal length of the object-glass is $\mathrm{I} 2 \mathrm{ft}$. $\mathrm{I}$ in. ; its clear aperture 8.52 in. ; and the power of its eye-pieces 135 to 396 . The diameter of its circles at the outer edge is $45^{\circ} 30$ in., and at the graduation 4340 in., both circles being divided to every two minutes. The power of the reading microscopes is $45^{\circ} 3$ diameters. Its collimators have a focal length of $2 \mathrm{ft}$. I I in: This instrument, under Profs. Newcomb, Harkness, and Eastman, and their assistants, has had for its chief work the more accurate determination of the stars whose places are computed in the Nautical Almanac, and of those needed by the Coast Survey. The chronograph, made by Alvan Clark, is of the form known as the

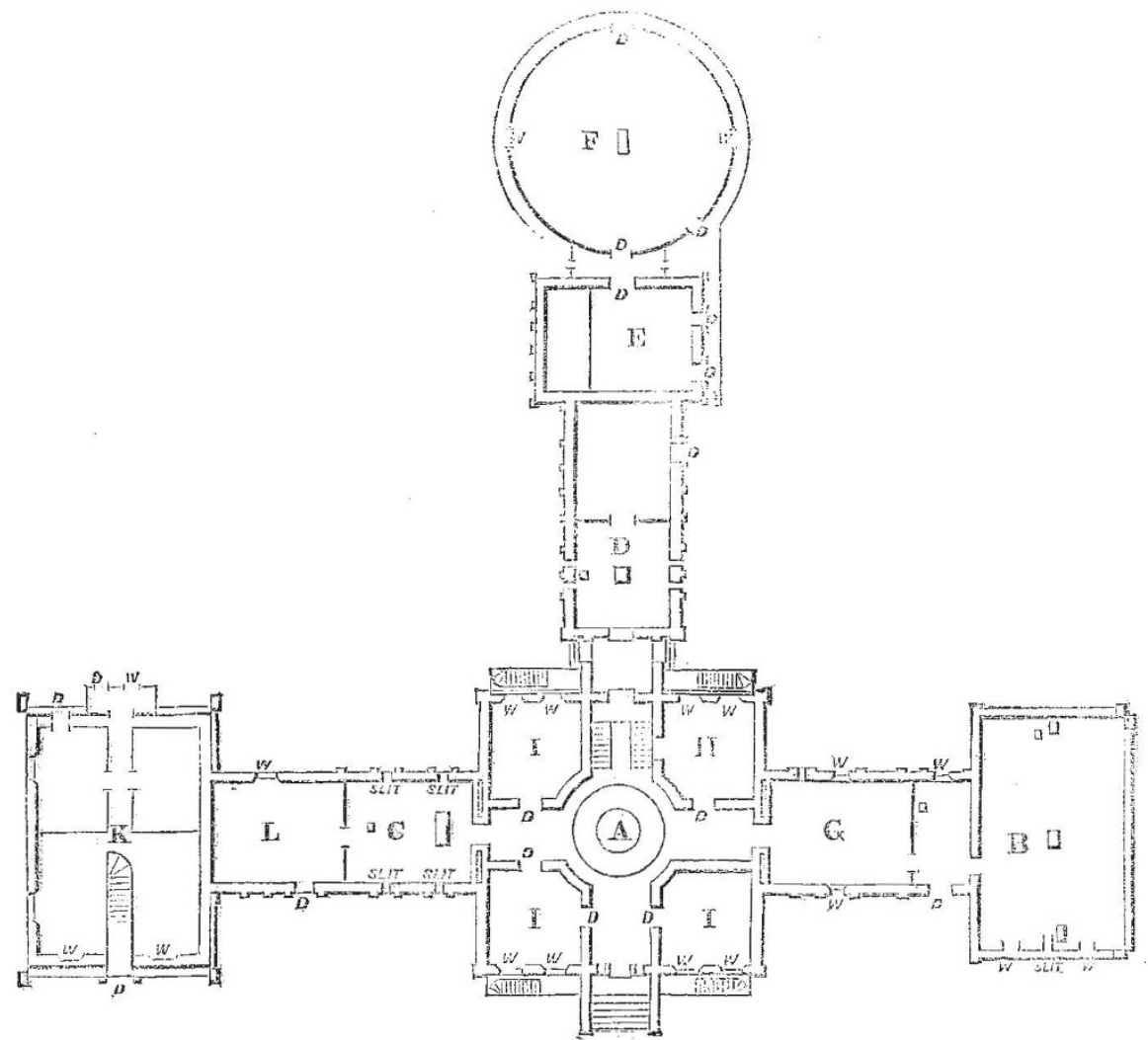

FIG. 6-The United States Naval Observatory-Ground Pian. A, Picr of Equatorial. B, Transit Circle. C, Mural Circle and Transit. D, Prime Vertical. E, Computer's Room for Great Equatorial. F, Great Equatorial. G, Library. H, Superintendent's Office. I, I, I, Offices. K, Super.

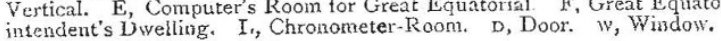

Hipp chronograph, with modifications by Prof. Harkness.

Passing to the eastern wing there are seen, side by side, the mural circle and the smaller transit instrument, with their clock and chronograph. The mural circle has an object-glass of $4 \%$ in., and a focal length of 5 it. $3.8 \mathrm{ios}$, the highest power of the eye-pieces being 240 . The diameter of the circle at its outer edge, where the graduation is placed, is $60.35 \mathrm{in}$. It is divided to every five minutes; the power of its reading microscope is 17.1 diameters. The transit has a focal length of $7 \mathrm{ft} .0^{\circ} 4 \mathrm{in}$., and its object-glass an aperture of $5.33 \mathrm{in}$.

The chronometer-room shows another and a distinct but important office of the observatory, The relation of all its work to the interests of practical navigation is sufficiently clear. More than 200 time-keepers have been at one time under care in this room. As many as eighty in 1867 were condemned and withdrawn from use. It is as gratifying as it is creditable to American skill to find that the chronometers of Messrs. Negus and Co., of New York, equal, if they do not excel, any of foreign workmanship.

From this room of the observatory the exact time is furnished daily at $\mathrm{I} 2 \mathrm{M}$. to the Western Union Telegraph Office in Washington for dispatch throughout the United States. The naval officer, standing by the standard mean clock, and having the astronomical correction of that clock also before him, at three minutes before $12 \mathrm{M}$. calls the telegraph operator at his office, and, at the instant of noon, taps the electric key, giving the time to the company's office. He also drops the dome ball. The chronometer-room is under the very efficient direction of Commander A. W. Johnson, U.S.N.

The seventeen annual volumes of astronomical and meteorological observations now published best set forth in themselves the work of the observatory. The latest of 
these volumes vie in extent and in value with the publi- for more than thirty years as its director. In 1840 Prof. cations of Greenwich and Paris. The star catalogue, Bartlett visited Europe for the United States Government, issued as Appendix No. I to the volume for $187 \mathrm{I}$, em- inspected and reported upon its chief observatories, subbraces more than 100,000 observations, giving the places of 10,000 stars. It is the twenty years' work of Prof. M. Yarnall, embracing the reduction of his own observations and those of others from the year I845 to I87I. The astronomer knows how to appreciate such a work.

Congress, in whose hands is the destiny of the institution, has promptly appreciated its claims, and does not withhold the liberal appropriations asked for it as due to astronomy and to this branch of naval efficiency.

West Point Observatory.-This observatory was erected in 1839 for astronomical purposes and the accommodation of the library of the Academy and its philosophical apparatus. The institution of an observatory is to be credited to Prof. W. H. C. Bartlett, LL.D., so well known mitting also a plan for an observatory at Washington, and purchasing for West Point whilst abroad its three large instruments, the equatorial, the transit, and the mural circle.

The transit instrument in the east tower was made $y b$ Ertel and Son, and its object-glass by Merz and Mähler, at Munich, the whole cost being about I,I 30 dols. It was mounted in 1843 , the memorable year for observatories in the United States. Its object-glass has a clear aperture of $4.62 \mathrm{in}$, and a focal length of $76.75 \mathrm{in}$. It is provided with four eye-pieces and one dark glass, and has an illuminating apparatus, giving either a bright field with dark lines, or a dark field with bright lines, which can be modified at will by means of a coloured wedge. The
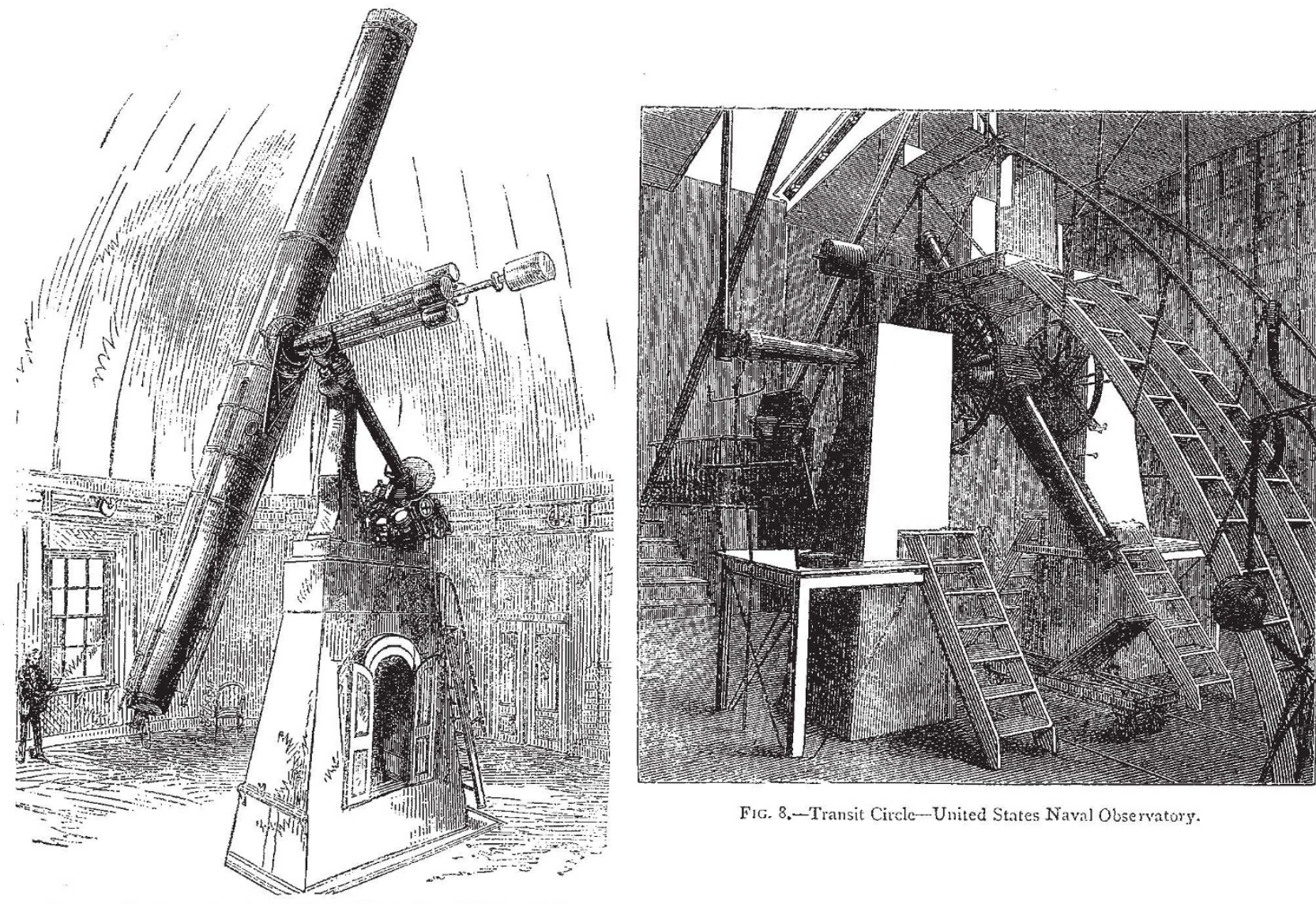

FIg. 8,-Transit Circle-United States Naval Observatory.

FIG. 7.-The Great Equatorial-United States Naval Obsc، vatory.

reticule has seven vertical and two horizontal lines. An $j$ extra vertical wire is driven in a horizontal direction by means of a micrometer screw, each division of which corresponds to $\mathrm{O}^{\prime \prime} \cdot 334$. It has a striding level, each small division being $\mathrm{I}^{\prime \prime} \cdot 23=0.0825$. The steel pivots have not sensibly changed their equality of dimensions since the instrument was mounted.

The west tower has the mural circle, by Troughton and Simms, of London. This was cast in one entire piece of brass. Its diameter is $5 \mathrm{ft}$, and its graduations are on two bands, one of gold, the other of palladium. The telescope has a clear aperture of 4 in., with a focal length of $60 \mathrm{in}$.

The central main tower has a revolving dome of $27 \mathrm{ft}$. in diameter, which rests on six 24-pound cannon-balls, turning between cast-iron annular grooves. The equa- torial, made by Mr. Henry Fitz, of New York, has a focat length of 14 ft., and a clear aperture of $9.3 \mathrm{in}$. It has thirteen eye-pieces. The hour circle reads to two seconds of time, and the declination circle to twenty seconds of an arc, each circle being $20 \mathrm{in}$, in diameter. This instrument cost 5,000 dols.

The sidereal clock, by Hardy, has a Bond break-circuit attachment, and is connected with the several instruments by wires and break-circuit keys. Besides these there are valuable portable instruments in the observatory, which lends them from time to time to topographical and surveying parties in the west and north-west, or to stations of the Engineer Corps, like the one at Willett's Point, New York. Several valuable additions, including a Bond chronograph, the odolites, and sextants, have been made within the last two years. 
The purposes of the observatory of the Academy are most effectively secured by confining its workings to the end of educating the cadets in the knowledge and practical use of the instruments. During the spring months they are taken in parties of two, three, or four to receive such instruction, and are required themselves to make observations with each instrument, and reduce them. During the summer encampment a month is devoted to further instruction in connection with a field observatory at Fort Clinton, where they use a field transit, zenith telescope, and other instruments. Each makes his own records, and works out his results for the ordinary problems of time, latitude, longitude. Würdeman of Washington is constructing for this field observatory a new transit and zenith telescope.

Although the chief design of the observatory has been from the first to secure such proficiency in the cadets as would prove of most value to them in the field work to which so many army officers are called, and although neither the professors nor their assistants, who are daily instructors in several other branches, can find time available for lengthened series of observations, still at different times valuable observations have been secured in the midst of pressing duties. Among these are those of Prof. Bartlett on the great comet of 1843 , published in the Transactions of the American Philosophical Society, and recent observations under Prof. Michie and his assistants, Lieut. Bass and others, for determining the Iongitude of the observatory.

Annapolis Observatory.-We cannot complete this sketch of the United States Government observatories without a just, though necessarily very brief, notice of the observatory used in the instruction of midshipmen at Annapolis.

The Department of Astronomy was created in 1853 , and until 1865 was in charge successively of Profs. Chauvenet and Coffin. Since that time a graduate of the
Academy has from time to time been in charge. The course in astronomy is of necessity limited, most of the midshipman's time in this department being required for

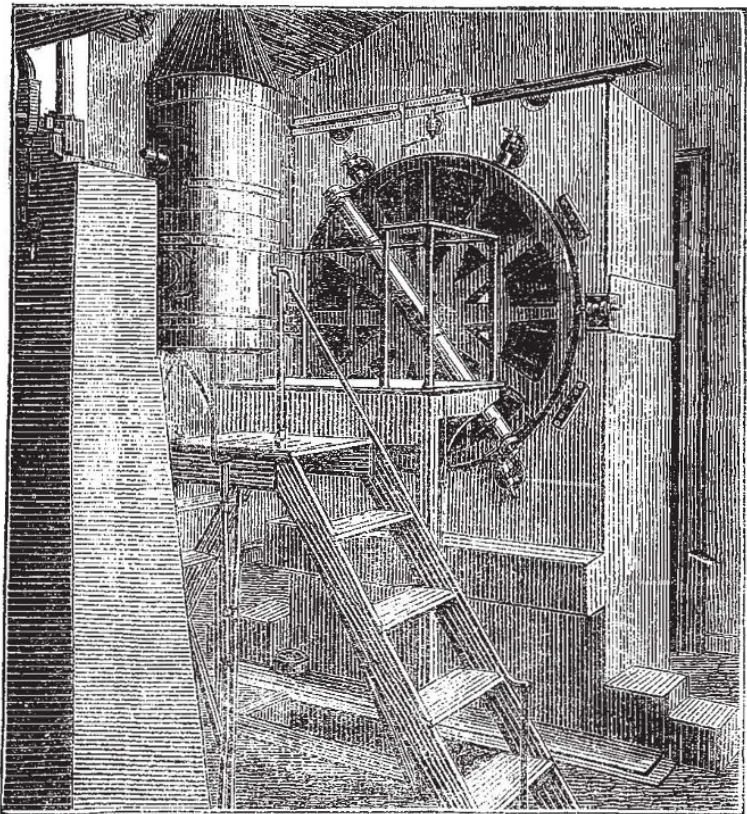

Fig. 9.-Murai Circle and Smaller Transit Instrument-United States Naval Observatory.

the study of practical navigation. We learn from the report of Lieutcnant-Commander R. L. Phythian to Admiral Porter in 1869 the following facts :- "The instru-

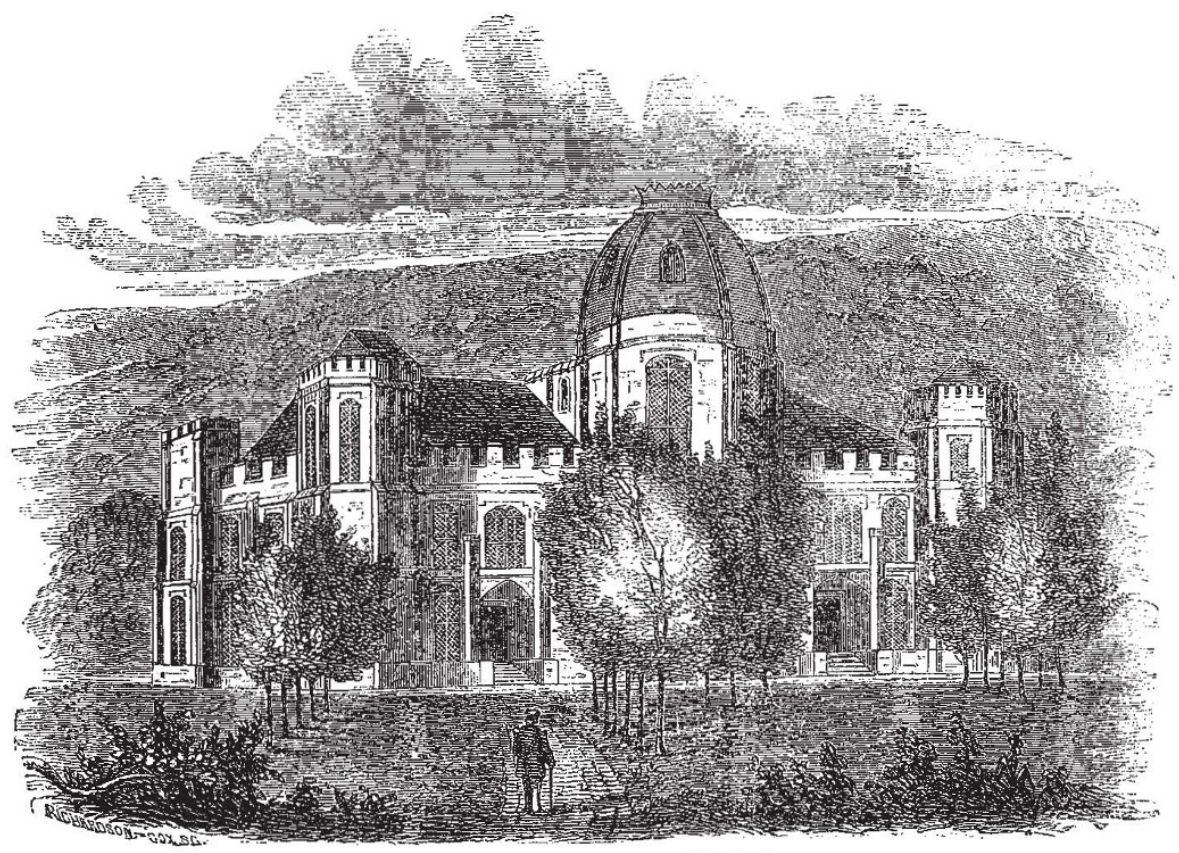

Fig. ro. - West Point Observatory - North Front.

ments used in this department are the chronometer, the sextant, the artificial horizon, the azimuth compass, the surveyor's chain and compass, the theodolite, and the plane-table. The observatory is supplied with a sidereal clock, an equatorially-mounted telescope, and a superior meridian clock. These instruments are used in instruc- tion only to show the midshipmen the principles of them. There is not sufficient time for them to acquire a practical knowledge of their use by observing with them."

Altogether the United States has reason to be proud of her observatories, and of the work already done by her astronomers. 